\title{
Features of Human Resource Management in Higher Education Institutions in the Context of the Transition to the Model "University 4.0"
}

\author{
Tatiana Kreydenko ${ }^{1,2}$, Tatiana Adashova ${ }^{1}$, Natalia Rogoten ${ }^{3}$ \\ ${ }^{1}$ Peoples' Friendship University of Russia (RUDN University), Russia \\ ${ }^{2}$ Financial University under the Government of the Russian Federation, Russia \\ ${ }^{3}$ Moscow Pedagogical State University, Russia \\ *Email: t.krejdenko@mail.ru
}

\begin{abstract}
The widespread introduction of digital technologies has led to a significant revision of the requirements for the qualification of employees, the transformation of staff competencies in connection with the change of work. Reducing the life cycle of professions, the emergence of new ones, increasing the requirement for flexibility and adaptability of personnel ("soft skills") and other requirements of the modern labor market have caused the need for fundamental changes in the system of training specialists in higher educational institutions. The development of higher education in universities of traditional models ceases to meet the demands of both employers and graduates themselves in terms of their professional training. Modern universities are not only scientific and educational, but also innovative and hightech enterprises of the economy, which should be ready not only to create new competencies and knowledge, but also to commercialize them. In such conditions, there are fundamental changes not only in the organization of the educational and research process at the university, but also significant changes in the types and level of competencies of the teaching staff. In this regard, there is a need to develop tools for optimizing the process of human resource development at the university based on the assessment of efficiency conditions. The authors analyze the need to review the requirements for the organization of the educational process in order to increase the efficiency of research, innovation and entrepreneurial activities in the university.
\end{abstract}

Keywords: High-Tech Enterprise, Human Resource Management, University 4.0, Education 4.0.

\section{INTRODUCTION}

The most significant factors of socio-economic, technological, and development of modern society that contribute to economic growth in the late twentieth and early twenty-first centuries were knowledge, innovation (including technological), and investment in human resources [4]. For the first time, the term "human resource development" was introduced into practice by Leonard Nadler in the United States in 1969 [6], at the same time in the works of D. McGregor, K. Argyris, F. Hertzberg and others formulated the basic foundations of the concept. By the end of the 90s, the development of human resources was considered as a mechanism for achieving compliance of the values of personnel quality indicators with the operational and strategic goals of the organization, achieved through the integrated use of training and development, career growth and organizational development [2]. In the future, this led to the transformation of the concept into "Strategic Human Resource Development" (Strategic Human Resource Development, or SHRD). From this point of view, the development of human resources of the organization ceases to be exclusively a personnel function and begins to unite all decision-makers aimed at improving the competitiveness of the organization in the market.

As a result, there is a gradual transformation of approaches to professional competencies, which are no longer fixed and static, but begin to change after the 
transformation of technological and organizational processes, thereby turning into "dynamic portfolios of competencies" [7]. In such conditions, the organization faces the need to form not a staff of employees, but a cumulative "portfolio of competencies" (organizational "skills stock") of employees of different professions, which is the basis for the formation of various sets of competencies necessary for solving specific tasks. As a result, the company is gradually changing its orientation from education and training ("Training and Development" (T\&D)) to development ("Learning and Development" (L\&D)) [11].

The initial formation of modern professional competencies takes place in universities, which, on the one hand, contribute to the high-tech and innovative development of society, and on the other hand, are themselves high-tech enterprises that form modern trends.

\section{A MODERN UNIVERSITY IS A HIGH- TECH ENTERPRISE}

The term "high-tech " (Hi-Tech) originated in the 50s of the twentieth century, but there is still a lot of uncertainty about both the concept and the criteria for referring to it. Among the most significant criteria are the research intensity (the cost of scientific research in the total cost of production should be at least $3.5 \%$, and for leading high-tech technologies should be at least $8.5 \%$ ), science yield, innovation and focus on commercialization of the results of scientific activity [8,9]. The role of hightech companies in the world economy is determined not only by the ability to produce goods and services with a high degree of knowledge intensity, but also by their ability to consolidate and disseminate new knowledge, create and implement advanced technologies at all stages of value creation [5].

A modern university is the result of a long development of the entire system of scientific knowledge. In the process of formation of the modern university system, several stages can be distinguished. The first two stages were quite long: the activity of the University 1.0 (XI - XVII centuries) was aimed at teaching, transmitting the cultural values of society and forming the necessary knowledge for it. University 2.0 (XVII - mid-XX centuries) contributed to the creation of a civil society, a national idea based not only on the organization of the learning process, but also on the formation of research skills.

The modern university is developing in the dynamic conditions of the University 3.0 (innovative university) model and its further transformation into University 4.0 (a model of universities that develops on a digital environment and combines physical and virtual space) [1]. University 3.0 is a platform for obtaining the necessary competencies, integrating the interests of science, business and education. This significantly reduces the degree of influence on its activities on the part of society and state authorities and independently forms a new request for the necessary competencies of graduates. This situation requires a serious review of the process of development of human resources of the University, a significant increase in the efficiency of using their scientific, innovative and educational potential. The implementation of the University 4.0 model will require intensive development not only of the "education" and "science" blocks, but also the formation of a comprehensive ecosystem, including the "innovation", "transformation" and "strategic management" blocks. The main engine of the formation of this ecosystem is university teachers. The effectiveness of their work in universities of this type directly depends on the structure of the tasks they perform [10].

The limitations associated with the 2020 pandemic have created conditions for the emergence of even more innovative models of universities of the future: the Platform University, Nomad University, Polymath University, etc. [3]. But the development of such models is impossible without revising the university's human resource management system, the structure of the job requirements of the teaching staff, the system for evaluating the effectiveness of their activities, which is primarily related to the academic load (since this is one of the main activities under the employment contract of the teaching staff).

\section{EVALUATION OF THE EFFECTIVENESS OF ACCOUNTING FOR THE ACADEMIC WORK OF STAFF FROM AMONG THE TEACHING STAFF AT THE UNIVERSITY}

The job responsibilities of the teaching staff of any university consist of several types of work: educational activities, educational and methodological, research, scientific and methodological, educational and organizational and methodological work. Labor law is governed by the total duration of working time of the teaching staff of the University - not more than 36 hours per week (article 333 of the Labor code) that given the 44 week duration of the school year, 56 calendar days leave and 12-14 public holidays approximately 1500 hours per year (Order of the Ministry of education and science of the Russian Federation dated 22 December 2014 No. 1601).

Educational and methodical activity as the process is controlled by the fact of the classroom activity from the Dean's office and educational department, the result of the activities evaluated in the framework of the interim and final certification, the independent examination during the period of accreditation of higher education 
institutions or within the framework of the evaluation and monitoring of educational achievements of students on a Single portal online testing in education. The structure of the annual workload is regulated by local regulations of the university. The norm of time for calculating the academic load in the classroom corresponds to 1 hour per group for 1 academic hour of lectures, seminars and laboratory classes. The standard of time for accounting for consulting sessions, monitoring within academic disciplines, organizing and conducting practices, managing coursework, final qualification works is calculated based on the relative time standards adopted at the university (for example, no more than $10 \%$ of the volume of independent work) or fixed ( 2 hours per group, 0.5 hours per job, etc.). Evaluation and control of other activities from the point of view of the process is carried out within the norms of the organization of the second half of the day by teachers, and as a result is evaluated according to the criteria adopted by local acts and taken into account in an effective contract: publication activity, the number of theses prepared and defended under the guidance of the teacher, diplomas and awards of student works at competitions and Olympiads at all levels performed under the guidance of the teacher, minutes of meetings of departments, Scientists and Dissertation Councils, etc. As an assessment of the result of these types of activities of a teacher, the university develops a system of minimum values of evaluation indicators.

By entering into an employment contract, the employee assumes responsibility for their performance, otherwise, he may be dismissed for non-compliance with official duties, demoted or not allowed to the next competitive selection for the right to hold his position.

The situation is hampered by the prevailing practice in the university, i.e. weak accounting standards during the second half of the day in teaching staff activities. And taking into account the existing order and norms of time for calculating the volume of academic work performed by the teaching staff, in which decreasing correction factors are applied to the real volume of classroom classes taken into account in the academic load, the implementation of annually growing indicators of an effective contract becomes poorly implemented. In such a situation, the number of hours of classroom work taken into account in the training load may be 1.5-2 times less than the actual number of classes held. In this situation, the employee will be forced to switch to a lower rate, increase the number of groups or disciplines read. This, in turn, significantly reduces the potential time for scientific research, organizational, methodological and other types of work, for which the reporting indicators also do not decrease, but increase.

In this regard, there is a need to assess the effectiveness of the current practice of organization of accounting of academic work load of employees from the faculty and develop recommendations to optimize treatment of the various types of teaching staff activities in the total working time. The effectiveness assessment is proposed to be carried out through several indicators.

1. Calculation of the minimum number of students required for admission to the 1st year for the effective formation of the teaching load of the teaching staff. The suggested methodology of this calculation takes into account the amount planned to be opened at the faculty profiles, baccalaureate, regulatory minimum number of students in the group ( 24 people) and a coefficient based on the projected reduction in the number of students for learning outcomes 1 and 2 of the course (1).

$N s=Q * N * K$,

where: $N s$ is the minimum number of students in the 1 st year, necessary for the effective formation of the academic load of the teaching staff working for 3-4 undergraduate courses

$Q$ - number of undergraduate profiles in the faculty;

$N$ - standard minimum number of students in the group;

$k$ - coefficient of accounting for the expected decrease in the number of students (calculated based on the average annual value of the share of students expelled over the past 4 years, taking into account data for the 1 st and 2 nd year).

When set equal to or greater than the minimum number of students for 1 course, the university has the right and opportunity to introduce reduction factors when calculating the workload of faculty members. If the number of students is below the minimum limit, the introduction of such coefficients becomes ineffective from the point of view of using the research potential of employees from among the teaching staff of departments and faculty. The option of limiting the number of profiles to open is inefficient, and its implementation can lead to even more problems. The existing undergraduate profiles were created 6-8 years ago, when developing their curricula, the main part of the disciplines of the professional block was assigned to the graduating departments. So, the participation in the implementation of educational programs of other departments does not exceed $8-10 \%$ of the total volume of classroom classes in the profile. As a result, the temporary absence of a profile even during one academic year can lead to a significant loss of academic load for the teaching staff of individual departments.

2. Assessment of the sustainability of the development of departments from the point of view of the implementation of undergraduate educational programs. The sustainability of a department of the university can be evaluated through the ratio of hours of disciplines of profile implemented by department staff to total number of hours of workload units. The lower its value, the more stable the department is in terms of academic load. 
3. Assessment of the openness of the bachelor's profile.

The degree of openness of the bachelor's profile can be an indicator of the competitiveness of its graduates. A wide range of academic disciplines studied for undergraduate students creates additional advantages in the labor market and when applying for a master's degree.

To assess the effectiveness of training undergraduate students, coefficients were calculated that reflect the degree of participation of the graduating department in the implementation of the corresponding curriculum (2).

Kop $=H$ dep $-H$ total

where: Kop - the degree of openness of the profile

$H$ dep - the number of academic hours of disciplines taught by teachers of the graduating department for students of the profile (3-4 year)

$H$ total - the total number of training hours of the profile disciplines (3rd and 4th year)

\section{EVALUATION OF THE EFFECTIVENESS OF ACCOUNTING FOR THE TRAINING WORK OF EMPLOYEES FROM AMONG THE TEACHING STAFF IN THE RUDN}

The testing of methodology for assessing the effectiveness of the accounting of the workload of staff from among the faculty in assessing the effectiveness of implementation of their functions was carried out based on the analysis of the educational process at the Peoples' Friendship University of Russia (RUDN University). RUDN is a classical university that trains highly qualified personnel at all levels of higher education (bachelor's and master's degrees), as well as training highly qualified personnel in postgraduate studies (it is a member of the Association of Classical Universities of Russia). One of the oldest structural divisions of the university is the Faculty of Economics, which includes 11 departments and more than 150 teachers, trains bachelors in 7 profiles of the direction of Economics and 3 profiles of the direction of Management.

The official structure of the RUDN in terms of the teaching staff is characterized by a somewhat more complex structure than in most Russian universities. At the conclusion of an employment contract, a teacher is accepted not for a position, but for a specific position: associate professor-researcher, professor-methodologist, professor of international level, etc. But the minimum and maximum values of the training load do not depend on the position held, but on the specific position. For individual positions, the indicators of an effective contract in terms of scientific and organizational and methodological work differ significantly.
Educational student groups are formed according to the following principle: 1-2 year - universal student groups, 3-4 year - profile. It was planned to switch from 2020 to a new format of admission of applicants, i.e. the recruitment to faculties and the formation of potential student groups should take place already taking into account the choice of profile from the 1 st year. But as a result of the 2020 pandemic, it was decided to postpone the transition to a new format.

One of the oldest structural divisions of the university is the Faculty of Economics, which consists of 11 departments and more than 150 teachers, training bachelors in 7 profiles of the direction of Economics and 3 profiles of the direction of Management.

The calculation of the minimum number of students required to enroll in 1 course for effective formation teaching load of faculty, sustainability departments and the openness profiles of bachelor of Economics showed that:

The minimum number of students at which the employment of teachers by the educational process in all 7 profiles will be most effective is 196 people.

The most stable department is the Department of Economic and Mathematical Modeling, which implements significant disciplines of the basic block.

The most open profile of the faculty is the profile "city economics" (where more than $50 \%$ of the disciplines are implemented not at the graduating department), the most closed - "accounting and audit", "project analysis".

The disbandment of the least stable departments can lead to the loss of entire scientific areas of the faculty, which in turn will have a negative impact on other profiles, and on the research work of the entire university. Thus, the existing practice of forming the load of the teaching staff of departments can lead to a decrease in the efficiency of using the innovative, scientific and educational potential of the human resources of the university.

\section{CONCLUSIONS}

Effective organization of the university ecosystem is impossible without optimizing the organization of the educational process. Based on the study, the following recommendations were developed:

1. When recruiting students for 1 year less than the minimum threshold number for opening all existing profiles (at least one for each graduating department), exclude the use of reducing coefficients for calculating the amount of training load of employees from the number of teaching staff.

2. Maintain approaches to the formation of profile student groups (choosing a profile at the end of the 2 nd 
year) until a steady increase in the number of applicants is achieved.

3. To activate the work of graduate departments at Open Days, in the media, with secondary educational institutions in order to popularize the profiles.

4. In the case of opening new profiles, it is mandatory to provide for the appropriate participation of all departments in the implementation of the educational program of the profile.

5. If the practice of applying lowering coefficients is maintained, it is possible to provide for a more flexible calculation of the average training load for teaching staff. Allow a decrease in the value within $10-15 \%$ of the total load, subject to the mandatory implementation of planned indicators for other types of work.

6. Expand the list of works carried out by teachers, taken into account in the calculation of the total load, including participation as a student of advanced training courses in the specialty. This will help to increase the innovative, educational and scientific potential of staff from among the teaching staff.

7. Develop a transparent system for evaluating the performance of additional types of work (outside the planned 1500 - hour total load) by analogy with the existing point-based system for evaluating the effectiveness of teaching staff activities. To involve the expert community from among the leading teachers of departments in the development) to take into account the peculiarities of the organization of research activities in various areas (the need for an experiment, field work, etc.with an assessment of the necessary factors and the probability of obtaining a positive result)

\section{ACKNOWLEDGMENTS}

This paper has been supported by the RUDN University Strategic Academic Leadership Program.

\section{REFERENCES}

[1] J.G. Foster, A. Rzhetsky, J.A. Evans, Tradition and innovation in scientist's research strategies., American Sociological Review Vol. 80 Iss. 5 (2015) 875-908.

[2] J.W. Gilley, S.A. Eggland, A.M. Gilley, Principles of Human Resource Development., MA: Perseus Publishing, 2002, 482 p.

[3] Hamilton Martin Envisioning Education 4.0-A scenario planning approach to predicting the future, Future Directions in Digital Information: Predictions, Practice, Participation. Chandos Digital Information Review, 2021, pp. 267-283. DOI: https://doi.org/10.1016/B978-0-12-822144$\underline{0.00015-X}$
[4] Paul M. Romer, Endogenous Technological Change. Journal of Political Economy Vol. 98 Iss. 5 Part 2 (1990) S71-S102. Retrieved from: https://www.nber.org/papers/w3210.pdf

[5] O.A. Tsukanova, E.A. Dubitskaya, The Fundamental View on High-Tech Enterprises and Their Role in the Economy, Journal of Legal and Economic Studies 1 (2018) 151-155.

[6] L.G. Batrakova, Evolution of scientific views on the concept of "Human Resources" and its modern specifics, Bulletin of the Pushkin State University 2 (2011) 46-68 (In Russ.).

[7] D.S. Volkova, Labor Market in the era of digital economy, Young Scientist 7(297) (2020) 158-160 (In Russ.).

[8] V.S. Vostrikov, High-tech companies as a factor of strategic development of the domestic economy, Creative Economy Vol. 9 Iss. 4 (2015) 473-484 (In Russ.).

[9] N.V. Glushak, On the issue of identifying high-tech industries and complexes, Creative Economy 4 (2017) 497-508.

[10] O.V. Narimanova, Concept University 3.0: prospects for implementation in Russia in the context of a new technological revolution, Personality in a Changing world: health, adaptation, development, Iss. 2(25), 2019. DOI: https://doi.org/10.23888/humJ20192350-363 (In Russ.)

[11] I.A. Esaulova, Human resource development: the evolution of concepts and practices, Labor Economics Vol. 5 Iss. 1 (2018) 13-28. DOI: https://doi.org/10.18334/et.5.1.38869 (In Russ.) 